\title{
Interferon-based therapy did not attenuate hepatitis C-associated rheumatic disorder risk: A nationwide population-based cohort study
}

\author{
Jur-Shan Cheng
}

Chang Gung Memorial Hospital

Jing-Hong Hu

Chang Gung Memorial Hospital

Yu-sheng Lin

Chang Gung Memorial Hospital

Ming-Shyan Lin

Chang Gung Memorial Hospital

Hsin-Ping Ku

Chang Gung Memorial Hospital

\section{Rong-Nan Chien}

Chang Gung Memorial Hospital

Ming-Ling Chang ( $\nabla$ mlchang8210@gmail.com )

Chang Gung Memorial Hospital https://orcid.org/0000-0003-4902-4401

\section{Original Research}

Keywords: HCV, rheumatic, interferon, TNHIRD, mortality

Posted Date: August 27th, 2020

DOI: https://doi.org/10.21203/rs.3.rs-64010/v1

License: (9) This work is licensed under a Creative Commons Attribution 4.0 International License.

Read Full License 


\section{Abstract}

\section{Background}

Whether hepatitis $\mathrm{C}$ virus (HCV) infection increases the risk of rheumatic disorders and whether the associated risk is reversed by anti-HCV therapy remain elusive. We aimed to investigate these topics.

Methods

A nationwide population-based cohort study of Taiwan National Health Insurance Research Database (TNHIRD) was conducted.

Results

Of 19,298,735 subjects, 3 TNHIRD cohorts (1:4:4, propensity score-matched), including HCV-treated (6,919 HCV-infected subjects with interferon and ribavirin therapy $\geq 6$ months), HCV-untreated $(n=27,676)$ and HCV-uninfected ( $n=27,676)$ cohorts, were enrolled and had been followed since 2003 to 2015 . HCVuninfected cohort had the lowest 11-year cumulative incidence of rheumatic disorders [9.535\%; $95 \%$ confidence interval (Cl): 8.416 10.734\%] ( $p<0.0001)$, while HCV-treated (14.95\%; 12.417 17.704\%) and HCV-untreated (14.999\%; 13.585 16.479\%) cohorts showed no difference in the cumulative incidences of rheumatic disorders $(p=0.8316)$. Multivariate analyses showed, HCV infection [hazard ratio (HR):1.671; 95\% Cl HR: $1.562-1.788, p<0.0001]$, female sex $(1.67 ; 1.565-1.782, p<0.0001)$, age $\geq 49$ years $(1.168 ; 1.088-$ $1.253, p<0.0001)$, Charlson comorbidity index $\geq 1$ (1.156; 1.074-1.245, $p=0.0001)$, liver cirrhosis $(0.795$; $0.674-0.937, p=0.0062)$, chronic obstruction pulmonary disease $(1.244 ; 1.134-1.364, p<0.0001)$, end stage renal disease $(0.732 ; 0.549-0.974, p=0.0326)$, diabetes mellitus $(0.91 ; 0.835-0.993, p=0.0333)$ and dyslipidemia $(1.205 ; 1.108-1.31, p<0.0001)$ were associated with incident rheumatic disorders. Among the 3 cohorts, the untreated cohort had the highest cumulative incidence of overall mortality $(29.163 \%$; $27.218-31.133 \%, p<0.0001)$, while the treated $(13.662 \% ; 11.389-16.140 \%)$ and un-infected $(9.99 \%$; 8.548 $11.559 \%)$ cohorts had indifferent mortalities $(p=0.1796)$.

Conclusions

$\mathrm{HCV}$ infection, baseline demographics and comorbidities were associated with the risks of rheumatic disorders. Although HCV-associated risk of rheumatic disorders might not be reversed by interferon-based anti-HCV therapy, which reduced the overall mortality in HCV-infected patients.

\section{Introduction}

Hepatitis $\mathrm{C}$ virus (HCV) is a human pathogen responsible for acute and chronic liver disease that infects an estimated 150 million individuals worldwide [1]. In addition to hepatic complications including cirrhosis and hepatocellular carcinoma, HCV may cause many extrahepatic complications such as diabetes mellitus (DM), hypolipidemia, cardiovascular events [1], and rheumatic disorders [2]. HCV is both hepatotropic and lymphotropic [3]. HCV lymphotropism represents the most important step in the 
pathogenesis of virus-related immunological diseases [4], especially rheumatic disorders. Rheumatologic extrahepatic manifestations are observed in $2-38 \%$ of HCV-infected patients [5], and this variability is attributed to the various geographic region and design of the studies [6-8]. Moreover, HCV antibodies were found in $18.5 \%$ among patients admitted to the rheumatology ward [9], being higher than the estimated global prevalence (2.2-2.8\%) of HCV infection [10]. HISPAMEC Registry showed, the systemic autoimmune diseases most associated with chronic HCV infection were Sjogren syndrome (SS), rheumatoid arthritis (RA) and systemic lupus erythematosus (SLE) [11]. Specifically, the co-prevalence of HCV and SS ranged from $49 \%$ [12] to $80 \%$ [13], HCV infection was found in $13 \%$ of a large series of Spanish patients with SS [14], and sicca symptoms were reported in $11 \%$ of French HCV patients [15]. HCV infection was also associated with increased RA risks [16-17], and the pooled prevalence of RA was $4.5 \%(0.6 \%-25.7 \%)$ of chronic HCV-infected patients in East Asia [2]. Moreover, the prevalence of HCV infection among SLE patients was found up be 10\% [18].

The combination of pegylated interferon (Peg-IFN) and ribavirin has provided a "cure" for a considerable proportion of patients with chronic hepatitis $\mathrm{C}$ infection $(\mathrm{CHC})$, particularly in patients with a favorable interferon $\lambda 3$ (IFNL3) genotype [1]. These cure rates were further improved by replacing interferon-based therapy with potent, direct-acting antiviral agents (DAAs) [1], and the sustained virological response rate (SVR) to DAA in HCV-infected patients is approaching 100\% [19]. However, some HCV-associated complications such as cardiometabiolic and oncogenic events cannot be reversed, even after viral clearance [1, 20-21]. Whether the HCV-associated risk of rheumatic disorders can be attenuated after the completion of anti-HCV therapy thus is still a crucial issue of public health in the era of DAA to eradicate HCV infection but remains elusive.

Accordingly, we conducted a nationwide population-based cohort study in Taiwan, a country where HCV infection is rampant [22]. The impacts of HCV infection and anti-HCV therapy on the risk of rheumatic disorders were investigated by comparing the cumulative incidences of rheumatic disorders and of the overall mortalities among HCV-infected subjects with and without anti-HCV therapy and the subjects without HCV infection, based on data from Taiwan National Health Insurance Research Database (TNHIRD). This database provides medical information of the nationwide population, which comprises $26,573,661$ individuals.

\section{Methods}

\section{TNHIRD samples and measurements}

This population-based retrospective cohort study used nation-level data, including the National Health Insurance (NHI) administrative database, the Cancer Registry Database, and the Death Registry Database of Taiwan. The mandatory, single-payer NHI program provides comprehensive coverage including ambulatory care, hospital services, laboratory tests, and prescription drugs. Over $99 \%$ of the population is enrolled in the program and approximately $90 \%$ of the healthcare organizations are contracted with $\mathrm{NHI}$ Administration. Given that Taiwan is a hyperendemic area for hepatitis B virus (HBV) infection, which is 
highly oncogenic, causes many hepatic complications and prominently biases the phenotype of HCV infection [23], the subjects diagnosed with HBV infection in the observation period (2003-2015), or with any baseline rheumatic disorders including RA [International Classification of Disease, Ninth. Revision, Clinical Modification (ICD-9-CM) code (714)], ankylosing spondylitis [ICD-9-CM code (720)], psoriatic arthopathy [ICD-9-CM code (696.0)], sicca syndrome (also called SS) [ICD-9-CM code (710.2), systemic sclerosis [ICD-9-CM code (710.1)], SLE [ICD-9-CM code (710.0)], Behcet's syndrome [ICD-9-CM code (136.1)], Raynaud's syndrome [ICD-9-CM code (443.0)], polyarteritis nodosa and allied conditions [ICD-9CM code (446)], and psoriasis [ICD-9-CM code (696.X)] or mortality occurred prior to 6 months after completing anti-HCV treatment (the baseline), when is the time to ensure therapeutic response, were excluded.

HCV-treated cohort included subjects who had HCV RNA test and received ribavirin and pegylated interferon (Peg-IFN) in 2003-2015. Their first HCV test was assumed to be the index date of diagnosis. The baseline for the HCV-treated cohort was the date of 6 months after completing the combination therapy. Untreated HCV-infected patients were those who had HCV test (HCV antibody or HCV RNA test) (their first HCV test was the index date), were diagnosed with HCV [The International Classification of Diseases, Ninth Revision, Clinical Modification (ICD-9-CM) codes: 070.41, 070.44, 070.51, 070.54, 070.70, 070.71, V02.62], were prescribed hepatoprotective agents (silymarin, liver hydrolysate, choline bitartrate, or ursodeoxycholic acid), but did not receive any anti-HCV therapy (ribavirin or peg-interferon). HCVuninfected individuals were who did not have HCV diagnosis or HCV tests, and received no hepatoprotective agents or anti-HCV therapy, and they were classified as being HCV-uninfected. The HCVtreated cohort was matched with untreated HCV-infected patients (HCV-untreated cohort) and with HCVuninfected individuals (HCV-uninfected cohort) through a propensity score matching method indicating the probability of receiving the combination therapy, was estimated by using a logistic model. The covariates in the model included sex (male, female), age (20-39, 40-49, 50-59, $\geq 60)$, NHI registration location (city, township, rural area), Charlson Comorbidity Index (CCI) score (0,1, $\geq 2)$, and year of the index date (2003-2006, 2007-2009, 2010-2012). This method was used to assure that the HCV-treated cohort and the selected counterparts were comparable in observed characteristics. The baselines for the $\mathrm{HCV}$-untreated and HCV-uninfected cohorts were assigned according to the period from the index date to the baseline of their matched counterparts of the HCV-treated cohort, and subjects with rheumatic disorder or mortality occurred before the baselines were not selected. The index date of the HCVuninfected individuals was the date of one of their physician visits randomly selected from their claims database. The matching process for the 3 cohorts was shown in Supplementary Fig. 1.

Outcomes were defined as the development of rheumatic disorders as mentioned above. Subjects were followed until the date of the event, death, or the end of follow-up (December 31, 2015), whichever came first. Date of death were adopted from the Death Registry database. For the HCV-treated group, only the rheumatic disorder or mortality occurred 6 months after the complement of anti-HCV therapy (the baseline) were recorded.

\section{Statistical analysis}


All statistical analyses were performed using the Statistical Analysis System ((SAS version 9.4, SAS Institute Inc., Cary, NC, USA) software. Continuous variables were analyzed using a Student's t-test or Analysis of variance, as appropriate, and categorical variables were analyzed using a chi-square test or

Fisher's exact test, as appropriate. Cumulative incidences of outcomes were estimated and compared by using the modified Kaplan-Meier method and the Gray method with death being a competing risk event. Sub-distribution hazards models for competing risks, an extension of Cox proportional hazards models taking competing mortality into consideration, were used to estimate adjusted hazard ratio of developing rheumatic disorders, adjusting for age, sex, $\mathrm{NHI}$ registration location, the $\mathrm{CCI}$ score, year of the index date, and comorbid liver cirrhosis, chronic obstructive pulmonary disease (COPD), end stage renal disease (ESRD), DM, hypertension, dyslipidemia, cardiovascular events (including percutaneous coronary intervention, coronary artery bypass graft, myocardial infarction, heart failure, cardiogenic shock, and peripheral vascular disease) and stroke. Statistical significance was defined at the $5 \%$ level

\section{Results}

\section{Baseline characteristics}

From a total of $19,298,735$ individuals between January 1,2003 , and December $31,2015,11,223,475$ patients without HBV infection and baseline rheumatic disorders were identified; 104,281 patients with HCV infection and 11,119,194 patients without HCV infection were eligible for the study. Of all, 3 cohorts including HCV-treated $(n=6,919)$, HCV-untreated $(n=27,676)$ and HCV-uninfected $(n=27,676)$ cohorts were enrolled (Fig. 1). The 3 cohorts were matched with the propensity scores (1:4:4), did not differ in demographic factors, residency, $\mathrm{CCl}$ score and index year, which were the covariates in the models to calculate propensity scores, although baseline comorbidities were not similar (Table 1). Compared with HCV-untreated cohorts, the HCV-treated cohort had higher rates of baseline cirrhosis, comparable rates of COPD, but lower rates of other comorbidities. Compared with the HCV-uninfected cohort, the HCV-treated cohort had higher rates of most comorbidities including cirrhosis, comparable rates of DM and cardiovascular events, but lower rates of dyslipidemia and stroke. Compared with the HCV-uninfected cohort, the HCV-untreated cohort had higher rates of all baseline comorbidities except stroke. To lineate the HCV-associated complications, we compared the baseline factors between the HCV-infected cohort, which was a combination of the HCV-treated and HCV-untreated cohorts, and HCV-uninfected cohort. The HCV-infected cohort had higher rates of all baseline comorbidities except indifferent rates of dyslipidemia and lower rates of stroke, than the HCV-uninfected cohort (Supplementary Table 1). 
Table 1

Baseline characteristics of the 3 HCV cohorts of TNHIRD.
(1)
(2)
(3)
$p$ values

Treated Untreated Uninfected (1)-(2) (1)-(3) (2)-(3)

$\begin{array}{llll}\mathbf{N} & 6,919 & 27,676 & 27,676\end{array}$

Gender, N, (\%)

Male

3,832

(55.38)

15,328

$(55.38)$

15,328

$(55.38)$

Female

3,087

12,348

$(44.62)$

12,348 ,

(44.62)

Age range (yrs), N,

(\%)

$\begin{array}{llll}\mathbf{2 0 - 3 9} & 1,312, & 5,247, & 5,248, \\ & (18.96) & (18.96) & (18.96) \\ \mathbf{4 0 - 4 9} & 1,811, & 7,243, & 7,244, \\ & (26.17) & (26.17) & (26.17) \\ \mathbf{5 0 - 5 9} & 2,443, & 9,774, & 9,772, \\ & (35.31) & (35.32) & (35.31) \\ \mathbf{2 6 0} & 1,353, & 5,412, & 5,412, \\ & (19.55) & (19.55) & (19.55)\end{array}$

Area, N, (\%)

city

1,482

(21.42)

5,928 ,

(21.42)

5,928,

(21.42)

1

1

1

township

2,174

(31.42)

8,696 ,

(31.42)

8,696 ,

rural area

3,263

13,052,

(47.16)

(31.42)

13,052,

(47.16)

CCl score, N, (\%)

$\begin{array}{lllllll}\mathbf{0} & 3,443, & 13,774, & 13,772, & 0.9999 & 1 & 0.9998 \\ & (49.76) & (49.77) & (49.76) & & & \\ \mathbf{1} & 2,138, & 8,550, & 8,552, & & \\ & (30.90) & (30.89) & (30.90) & & \\ & >=2 & (1,338, & 5,352, & 5,352, & & \\ & (19.34) & (19.34) & (19.34) & & \end{array}$

TNHIRD: Taiwan National Health Insurance Research Database; HCV: hepatitis C virus; CCl: Charlson Comorbidity Index; COPD: Chronic obstructive pulmonary disease; ESRD: end stage renal disease; DM: diabetes mellitus. 


\begin{tabular}{|c|c|c|c|c|c|c|}
\hline & (1) & $(2)$ & (3) & \multicolumn{3}{|l|}{$p$ values } \\
\hline \multicolumn{7}{|l|}{ index_yr, N, (\%) } \\
\hline $2003-2006$ & $\begin{array}{l}3,601 \\
(52.05)\end{array}$ & $\begin{array}{l}\text { 14,404, } \\
(52.05)\end{array}$ & $\begin{array}{l}\text { 14,404, } \\
(52.05)\end{array}$ & 0.9997 & 1 & 0.9992 \\
\hline 2007-2009 & $\begin{array}{l}2,274 \\
(32.87)\end{array}$ & $\begin{array}{l}9,099 \\
(32.88)\end{array}$ & $\begin{array}{l}9,096 \\
(32.87)\end{array}$ & & & \\
\hline 2010-2012 & $\begin{array}{l}\text { 1,044, } \\
(15.09)\end{array}$ & $\begin{array}{l}4,173 \\
(15.08)\end{array}$ & $\begin{array}{l}4,176 \\
(15.09)\end{array}$ & & & \\
\hline \multicolumn{7}{|l|}{$\begin{array}{l}\text { Baseline factor, N, } \\
(\%)\end{array}$} \\
\hline Liver cirrhosis & $\begin{array}{l}695 \\
(10.04)\end{array}$ & $1,685,(6.09)$ & $9,(0.03)$ & $\begin{array}{l}<.0001 \\
0\end{array}$ & $\begin{array}{l}< \\
0.0001\end{array}$ & $\begin{array}{l}< \\
0.0001\end{array}$ \\
\hline COPD & $775,(11.2)$ & $\begin{array}{l}3,160 \\
(11.42)\end{array}$ & $2548,(9.21)$ & 0.6114 & $\begin{array}{l}< \\
0.0001\end{array}$ & $\begin{array}{l}< \\
0.0001\end{array}$ \\
\hline ESRD & $47,(0.68)$ & $722,(2.61)$ & $81,(0.29)$ & $\dot{0} .0001$ & $\begin{array}{l}<.0001 \\
0.000\end{array}$ & $\begin{array}{l}<.0001 \\
0.00\end{array}$ \\
\hline DM & $\begin{array}{l}\text { 1,320, } \\
(19.08)\end{array}$ & $\begin{array}{l}6,166 \\
(22.28)\end{array}$ & $\begin{array}{l}5,004 \\
(18.08)\end{array}$ & $\begin{array}{l}<.0001 \\
0\end{array}$ & 0.0549 & $\begin{array}{l}< \\
0.0001\end{array}$ \\
\hline Hypertension & $\begin{array}{l}2,011 \\
(29.06)\end{array}$ & $\begin{array}{l}9,485 \\
(34.27)\end{array}$ & $\begin{array}{l}7,422 \\
(26.82)\end{array}$ & $<.0001$ & 0.0002 & $\hat{0}_{0.0001}$ \\
\hline Dyslipidemia & $\begin{array}{l}815 \\
(11.78)\end{array}$ & $\begin{array}{l}5,268 \\
(19.03)\end{array}$ & $4,815,(17.4)$ & $\begin{array}{l}<.0001 \\
0\end{array}$ & $\begin{array}{l}< \\
0.0001\end{array}$ & $\begin{array}{l}< \\
0.0001\end{array}$ \\
\hline $\begin{array}{l}\text { Cardiovascular } \\
\text { events }\end{array}$ & $165,(2.38)$ & 1059, (3.83) & $685,(2.48)$ & $<.0001$ & 0.6642 & $\begin{array}{l}<.0001 \\
0.00\end{array}$ \\
\hline Stroke & $227,(3.28)$ & $1369,(4.95)$ & 1407, (5.08) & $<.0001$ & <. 0001 & 0.4593 \\
\hline $\begin{array}{l}\text { TNHIRD: Taiwan Nati } \\
\text { Comorbidity Index; CC } \\
\text { diabetes mellitus. }\end{array}$ & lealth Ins & e Research & base; HCV: & itis 0 & ; $\mathrm{CCl}$ & $\begin{array}{l}\text { tarlson } \\
\text { ase; DM: }\end{array}$ \\
\hline
\end{tabular}

\section{Cumulative incidences and associated factors of rheumatic disorders}

The HCV-treated, untreated, and uninfected cohorts were followed up until 2015 or death, with the longest observation of 11 years. Rheumatic disorders occurred cumulatively at 11 years in $14.95 \%, 14.999 \%$, and 9.535\% of the HCV-treated, untreated, and uninfected cohorts, respectively (Fig. 2, Table 2). The HCVuninfected cohort had the lowest cumulative incidence of rheumatic disorders among the 3 cohorts. However, no difference of cumulative incidences of rheumatic diseases was identified between the HCVtreated and HCV-untreated cohorts. The multivariate analysis of the 3 cohorts showed, compared with the 
HCV-uninfected cohort, both the HCV-treated and HCV-untreated cohorts had higher hazard ratios (HRs) to develop rheumatic disease. In addition, female sex, baseline age $\geq 49$ years, $\mathrm{CCl}$ score $\geq 1$, baseline COPD and dyslipidemia were associated with increased HRs of rheumatic diseases, while baseline liver cirrhosis, ESRD and DM were associated with decreased HRs of rheumatic diseases (Supplementary Fig. 2). Given that HCV-treated and HCV-untreated cohorts yielded similar HRs to develop rheumatic disorders, we thus combined HCV-treated and HCV-untreated cohorts to form HCV-infected cohort as mentioned above and compared the HCV-infected cohort with the HCV-uninfected cohort to view the impact of HCV infection on the development of rheumatic disorders. In addition to sex, age, $\mathrm{CCl}$ score, baseline COPD, dyslipidemia, cirrhosis, ESRD and DM, HCV infection was significantly associated with the development of rheumatic disorders, with a HR of 1.671 (Fig. 3).

Table 2

Comparison of the cumulative incidences of rheumatic disorders among (1) HCV-treated, (2) HCVuntreated and (3) HCV-uninfected cohorts.

\begin{tabular}{|c|c|c|c|c|c|c|c|}
\hline $\begin{array}{l}\text { Rheumatic } \\
\text { disorders }\end{array}$ & (1) Treated & $\begin{array}{l}\text { (2) } \\
\text { Untreated }\end{array}$ & $\begin{array}{l}\text { (3) } \\
\text { Uninfected }\end{array}$ & $p$ values & & & \\
\hline & & & & $(1)(2)$ & $(1)-(2)$ & (1)-(3) & (2)-(3) \\
\hline Number & 6,919 & 27,676 & 27,676 & & & & \\
\hline $\begin{array}{l}\text { Follow-up } \\
\text { (years), } \\
\text { mean } \pm S D\end{array}$ & $4.61+/-1.90$ & $4.62+/-1.07$ & $4.89+/-1.96$ & & & & \\
\hline $\begin{array}{l}\text { Event } \\
\text { number, N } \\
(\%)\end{array}$ & $503(7.27)$ & $2140(7.73)$ & $1310(4.73)$ & & & & \\
\hline $\begin{array}{l}\text { Competing } \\
\text { mortality, N } \\
\text { (\%) }\end{array}$ & $281(4.06)$ & $\begin{array}{l}3,478 \\
(12.57)\end{array}$ & $1316(4.10)$ & & & & \\
\hline $\begin{array}{l}\text { Cumulative } \\
\text { incidence, \% } \\
(95 \% \mathrm{Cl})\end{array}$ & $\begin{array}{l}14.95 \\
(12.417- \\
17.704)\end{array}$ & $\begin{array}{l}14.999 \\
(13.585- \\
16.479)\end{array}$ & $\begin{array}{l}9.535 \\
(8.416- \\
10.734)\end{array}$ & $\begin{array}{l}<.0001 \\
0.00\end{array}$ & 0.8316 & $\begin{array}{l}< \\
0.0001\end{array}$ & $\begin{array}{l}<.0001 \\
0.001\end{array}$ \\
\hline
\end{tabular}

\section{Cumulative incidences of mortality}

Of the 3 cohorts, the HCV-untreated cohort had the highest cumulative incidence $(29.163 \%)$ of overall mortality at 11 years $(p<0.0001)$. The HCV-treated and HCV-uninfected cohorts yielded indifferent mortality rates $(p=0.1796)$ (Table 3$)$. 
Table 3

Comparison of the cumulative incidences of overall mortality among (1) HCV-treated, (2) HCV-untreated and (3) HCV-uninfected cohorts.

\begin{tabular}{|c|c|c|c|c|c|c|c|}
\hline $\begin{array}{l}\text { Overall } \\
\text { mortality }\end{array}$ & (1) Treated & $\begin{array}{l}\text { (2) } \\
\text { Untreated }\end{array}$ & $\begin{array}{l}\text { (3) } \\
\text { Uninfected }\end{array}$ & $p$ values & & & \\
\hline & & & & $\left(\begin{array}{l}1 \\
(3)(2)\end{array}\right.$ & (1)-(2) & (1)-(3) & (2)-(3) \\
\hline Number & 6,919 & 27,676 & 27,676 & & & & \\
\hline $\begin{array}{l}\text { Follow-up } \\
\text { (years), mean } \\
\pm S D\end{array}$ & $\begin{array}{l}4.82 \\
+/-1.84\end{array}$ & $\begin{array}{l}4.86 \\
+/-2.03\end{array}$ & $5.03+/-1.91$ & & & & \\
\hline $\begin{array}{l}\text { Event number, } \\
\mathrm{N}(\%)\end{array}$ & 304 (4.39) & $\begin{array}{l}3,669 \\
(13.26)\end{array}$ & $\begin{array}{l}1,170 \\
(4.23)\end{array}$ & & & & \\
\hline $\begin{array}{l}\text { Cumulative } \\
\text { incidence, \% } \\
(95 \% \mathrm{Cl})\end{array}$ & $\begin{array}{l}13.662 \\
(11.389- \\
16.140)\end{array}$ & $\begin{array}{l}29.163 \\
(27.218- \\
31.133)\end{array}$ & $\begin{array}{l}9.99 \\
(8.548- \\
11.559)\end{array}$ & $\begin{array}{l}< \\
0.0001\end{array}$ & $\begin{array}{l}<.0001 \\
0.00\end{array}$ & 0.1796 & $<0.0001$ \\
\hline
\end{tabular}

\section{Discussion}

The most compelling results of the current study are as follows: (1) The HCV-uninfected cohort had the lowest cumulative incidence of rheumatic disorders among the 3 cohorts, while indifferent cumulative incidences were identified between the HCV-treated and HCV-untreated cohorts. (2) HCV infection, female gender, baseline age $\geq 49$ years, CCI score $\geq 1$, baseline COPD and dyslipidemia were associated with increased HRs of rheumatic disorders, while baseline liver cirrhosis, ESRD and DM were associated with decreased HRs. (3) The HCV-untreated cohort had the highest cumulative incidence of overall mortality at 11 years, while HCV-treated and HCV-uninfected cohorts yielded indifferent mortality rates.

The higher rate of baseline cirrhosis in the HCV-treated than the HCV-untreated cohorts of TNHIRD was coincided with the fact that only patients with significant fibrosis were reimbursed with anti-HCV therapy [24], and the other different baseline variables between these 2 cohorts highlight the idea that patients with comorbidities were ineligible for the interferon-based therapy and had been excluded for anti-HCV therapy. The different rates in baseline variables between HCV-infected and HCV-uninfected cohorts were consistent with the phenomenon that HCV infection elicits many cardiometabolic events and hypolipidemia [1]. Therefore, the baseline comparisons of the 3 cohorts supported the reliability of the data based on TNHIRD.

The facts that the HCV-uninfected cohort had the lowest cumulative incidence of rheumatic disorders, and HCV infection increased the HR of developing rheumatic disorders based on multivariate analyses endorsed the concept that HCV infection might cause rheumatic disorders, despite some studies did not support the participation of HCV infection in the pathogenesis of RA [25-27]. However, given that the HRs 
in developing rheumatic disorders between the HCV-treated and HCV-untreated cohorts were indifferent, the HCV-associated risk of rheumatic disorders might not be attenuated by interferon-based anti-HCV therapy. In particular, cryoglobulinemic vasculitis represents the prototype of HCV-related rheumatic disorders [28], long-term mixed cryoglobulinemia after SVR is common since cryoglobulin-generating B lymphocytes might have reached an HCV-independent autonomous phase before viral clearance [29]. $\mathrm{HCV}$-associated rheumatic disorder therefore might persist despite viral clearance. Moreover, whether interferon-based therapy reduces the risk of RA had remained conflicting [30-31], and interferon-based anti-HCV therapy may work as a "trigger" for RA [32-33] or SLE [34] had been showed in some case reports. Although treatment with interferon-alpha may lead to substantial clinical improvement of HCVrelated arthritis even without a complete biochemical or virological response [35], autoimmune disorders indeed occur in $4-19 \%$ of patients receiving interferon-based anti-HCV therapy and the associated symptoms developed between 2 weeks and 7 years after initiation of therapy [36]. The interferon-based anti-HCV therapy thus has been contraindicated for many rheumatologic autoimmune/inflammatory disorders based on the concern of triggering rheumatic disorders. New oral interferon-free combinations of various DAAs offer an opportunity for HCV-infected patients with rheumatic disorders to be cured with a short treatment duration and a low risk of side effects [37]. However, SVR following DAA might lead to immune reconstitution as tuberculosis reactivation had been reported [38]. Whether DAA therapy precisely attenuates the risks of HCV-associated rheumatic disorder without introducing other harm as mentioned above [38] demands further investigation.

On the other hand, that female sex and baseline age $\geq 49$ years are positively associated with the increased HRs of rheumatic disorders is consistent with the fact that female sex and old age had been identified as risk factors for RA [39]. CCl score $\geq 1$ and baseline COPD were associated with increased HRs of rheumatic disorders coincides that comorbidities including respiratory disease were more common in patients with RA at diagnosis than controls [40]. Patients with rheumatic disorders have increased prevalence of metabolic syndrome including dylipidemia [41] and acute myocardial infarction risk increased by 38\% [42] in RA patients might explained why dyslipidemia were associated with increased HR of rheumatic diseases. Of note, that baseline liver cirrhosis, ESRD and DM are associated with reduced HRs of rheumatic disorders is a novel finding. Interestingly, the connections with cirrhosis are variable among different rheumatic disorders. For example, the overall incidences of cirrhosis were reported to be lower in the RA cohort than in the non-RA cohort [43-44], while patients with psoriasis were found to have increased risk of cirrhosis than patients without psoriasis [44]. With regard to ESRD and $\mathrm{DM}$, in contrast to their negative associations with the rheumatic disorder risks, chronic kidney disease is a common complication of rheumatic disorders [45], patients undergoing hemodialysis therapy may develop serious rheumatic complications [46], newly diagnosed RA patients are at higher risk of DM [47] and the prevalence of DM is higher in patients with psoriatic arthritis compared with the general population [48]. That rheumatic disorders might be mistaken as ESRD- or DM-related complications in patients with ESRD and DM potentially explains the paradox.

Among the 3 cohorts, the HCV-untreated cohort yielded the highest overall mortality, which might be caused by other HCV-associated events such as cirrhosis, HCC or cardiometabolic events [1] other than 
rheumatic disorder-associated complications, since HCV-treated and HCV-uninfected cohorts had indifferent mortalities although the latter obviously had lower risk of rheumatic disorders. This phenomenon indicates the importance to prescribe anti-HCV therapy in HCV-infected patients in decreasing overall mortality, regardless of the risk for rheumatic disorders.

There are limitations recognized in the current study. First, because linking the results from TNHIRD to the laboratory results of individual patients was forbidden for privacy protection, the correlation of SVR with rheumatic disorders could not be identified. However, we are confident of the antiviral efficacy in the HCVtreated cohort since interferon-based therapy for HCV infection generally achieves an SVR rate up to $90 \%$ in Taiwan [49], where a favorable genetic variation in IFNL3 is prevalent [49]. Second, as mentioned above, interferon-based therapy might elicit rheumatic disorders in SVR patients $[32-34,36]$ and blunt the impact of viral clearance in attenuating rheumatic disorder risks. Third, because most of the rheumatic diseases accounted for the minority of the whole population and our preliminary statistical tests did not show any significance for any individual rheumatic disease, we thus had put all rheumatic diseases together as rheumatic disorders to yield the maximal statistical power. Some specific rheumatic diseases might have different connections with HCV infection or anti-HCV therapy. Anyhow, that SVR did not reduce the incidences of SLE and RA in CHC patients [50] supported our observation. Future prospective studies in other independent large cohorts with identifiable SVR following DAA therapy, subgroup analyses for specific rheumatic diseases and sophisticated molecular investigations are required to elucidate the fundamental mechanisms underlying the findings described here.

\section{Conclusions}

Taken together, HCV infection, female sex, baseline age $\geq 49$ years, and other comorbidities were associated with risks of rheumatic disorders. Although interferon-based therapy did not attenuate the rheumatic disorder risk, it indeed decreased the overall mortality of HCV-infected patients. These findings may merit further study for preventing or treating rheumatic disorders in HCV-infected patients.

\section{Abbreviations}

HCV: hepatitis C virus; TNHIRD:Taiwan National Health Insurance Research Database; Cl:confidence interval; HR:hazard ratio; DM:diabetes mellitus; SS:Sjogren syndrome; RA:rheumatoid arthritis; SLE:systemic lupus erythematosus; Peg-IFN:pegylated interferon; CHC:hepatitis C infection; IFNL3:interferon $\lambda$ 3; DAAs:direct-acting antivirals; SVR:sustained virological response rate; $\mathrm{NHI}$ National Health Insurance; HBV:hepatitis B virus; ICD-9-CM:International Classification of Disease, Ninth. Revision, Clinical Modification; SAS:Statistical Analysis System; COPD:chronic obstructive pulmonary disease; ESRD:end stage renal disease

\section{Declarations}

\section{Ethics approval and consent to participate}


The study protocol conformed to the ethical guidelines of the 1975 Declaration of Helsinki and was approved by the local Institutional Review Board. The need for consent was waived because the nationallevel data used in this study were de-identified by encrypting personal identification information.

\section{Consent for publication}

Not applicable.

\section{Availability of data and materials}

The datasets used and/or analysed during the current study are available from the corresponding author on reasonable request.

\section{Competing interests}

The authors declare that they have no competing interests.

\section{Funding}

This study was supported by grants from the Chang Gung Medical Research Program (CMRPG3I0412 and CMRPG3K0721) and the National Science Council (MOST 108-2314-B-182-051-, MOST 109-2314-B182-024- and MOST 109-2629-B-182-002-). The funders had no role in study design, data collection and analysis, decision to publish, or preparation of the manuscript. The opinions expressed in this paper are those of the authors and do not necessarily represent those of Chang Gung Medical Hospital and National Science Council, Taiwan.

\section{Authors' contributions}

JSC: study implementation and manuscript drafting

JHH, YSL, MSL, and RNC: data collection and manuscript writing.

HPK: statistical analysis and manuscript writing.

MLC: study design and implementation, manuscript drafting, and critical revision of the manuscript for important intellectual content.

All authors read and approved the final manuscript.

\section{Acknowledgements}

The authors thank Ms. Shu-Chun Chen, Ms. Chia-Hui Tsai, Mr. Chun-Kai Liang and Mr. Shuen-Shian Shiau from the Liver Research Center, Chang Gung Memorial Hospital, Taiwan, for their assistance with data mining. 


\section{References}

1. Chang ML. Metabolic alterations and hepatitis C: From bench to bedside. World J Gastroenterol. 2016;22(4):1461-76.

2. Younossi ZM, Henry L, Ong P. J, et al. Systematic review with meta-analysis: extrahepatic manifestations in chronic hepatitis $\mathrm{C}$ virus-infected patients in East Asia. Aliment Pharmacol Ther. 2019;49(6):644-53.

3. Sebastiani M, Giuggioli D, Colaci M, Fallahi P, Gragnani L, Antonelli A, Zignego AL. Ferri C.HCVRelated Rheumatic Manifestations and Therapeutic Strategies. Curr Drug Targets. 2017;18(7):80310.

4. Calvaruso V. Craxì A.Immunological alterations in hepatitis $\mathrm{C}$ virus infection. World $\mathrm{J}$ Gastroenterol. 2013 Dec;21(47):8916-23. 19(.

5. Sayiner ZA, Haque U, Malik MU, Gurakar A. Hepatitis C virus infection and its rheumatologic implications. Gastroenterol Hepatol (N Y). 2014 May;10(5):287-93.

6. Cacoub P, Renou C, Rosenthal E, et al. Extrahepatic manifestations associated with hepatitis $C$ virus infection. A prospective multicenter study of 321 patients. The GERMIVIC Groupe d'Etude et de Recherche en Medecine Interne et Maladies Infectieuses sur le Virus de l' Hepatite C. Med (Baltim). 2000;79(1):47-56.

7. Mohammed RH, ElMakhzangy HI, Gamal A, et al. Prevalence of rheumato-logic manifestations of chronic hepatitis C virus infection among Egyptians. Clin Rheumatol. 2010;29(12):1373-80.

8. Palazzi C, Olivieri I, Cacciatore P, Pennese E, D'Amico E. Difficulties in the differential diagnosis between primitive rheumatic diseases and hepatitis $C$ virus-related disorders. Clin Exp Rheumatol. 2005;23(1):2-6.

9. El Garf A, El Zorkany B, Gheith R, Sheba H, Abdel Moneim G. El Garf K.Prevalence and clinical presentations of hepatitis $C$ virus among patients admitted to the rheumatology ward. Rheumatol Int. 2012 Sep;32(9):2691-5.

10. Mohd Hanafiah K, Groeger J, Flaxman AD, Wiersma ST. Global epidemiology of hepatitis C virus infection: new estimates of age-specific antibody to HCV seroprevalence. Hepatology. 2013;57:1333-42.

11. Ramos-Casals M, Muñoz S, Medina F, et al. Systemic autoimmune diseases in patients with hepatitis C virus infection: characterization of 1020 cases (The HISPAMEC Registry). J Rheumatol. 2009;36(7):1442-8.

12. Pawlotsky JM, Ben Yahia M, Andre C, Voisin MC, Intrator L, Roudot-Thoraval F, Deforges L, Duvoux C, Zafrani ES, Duval J. Immunological disorders in $\mathrm{C}$ virus chronic active hepatitis: a prospective casecontrol study.Hepatology. 1994 Apr; 19(4):841-8.

13. Loustaud-Ratti V, Riche A, Liozon E, et al. Prevalence and characteristics of Sjögren's syndrome or Sicca syndrome in chronic hepatitis C virus infection: a prospective study. J Rheumatol. 2001;28(10):2245-51. 
14. Brito-Zerón P, Gheitasi $H$, Retamozo S, Bové A, Londoño M, Sánchez-Tapias JM, Caballero $M$, Kostov B, Forns X, Kaveri SV. Ramos-Casals M. How hepatitis C virus modifies the immunological profile of Sjögren syndrome: analysis of 783 patients. Arthritis Res Ther. 2015 Sep;10:17:250.

15. Cacoub P, Poynard T, Ghillani P, Charlotte F, Olivi M, Piette JC, Opolon P. Extrahepatic manifestations of chronic hepatitis C. MULTIVIRC Group. Multidepartment Virus C. Arthritis Rheum. 1999;42:220412.

16. Su FH, Wu CS, Sung FC, et al. Chronic hepatitis $\mathrm{C}$ virus infection is associated with the development of rheumatoid arthritis: a nationwide population-based study in Taiwan. [PLoS One. 2014;9(11):e113579.

17. Kudaeva FM, Speechley MR, Pope JE. A systematic review of viral exposures as a risk for rheumatoid arthritis. Semin Arthritis Rheum. 2019;48(4):587-96.

18. Mercado U, Avendaño-Reyes M, Araiza-Casillas R, Díaz-Molina R. Prevalance of antibodies against hepatitis $C$ and $B$ viruses in patients with systemic lupus erythematosus [in Spanish]. Rev Gastroenterol Mex. 2005;70(4):399-401.

19. Vermehren J, Park JS, Jacobson I, et al. Challenges and perspectives of direct antivirals for the treatment of hepatitis C virus infection. J Hepatol. 2018;69:1178-87.

20. Toyoda $\mathrm{H}$, Kumada $\mathrm{T}$, Tada $\mathrm{T}$, et al. Risk factors of hepatocellular carcinoma development in noncirrhotic patients with sustained virologic response for chronic hepatitis $\mathrm{C}$ virus infection. $\mathrm{J}$ Gastroenterol Hepatol. 2015;30:1183-9.

21. Kalaitzakis E, Gunnarsdottir SA, Josefsson A, et al. Increased risk for malignant neoplasms among patients with cirrhosis. Clin Gastroenterol Hepatol. 2011;9:168-74.

22. Hu JH, Chen MY, Yeh CT, et al. Sexual Dimorphic Metabolic Alterations in Hepatitis C Virus-infected Patients: A Community-Based Study in a Hepatitis B/Hepatitis C Virus Hyperendemic Area. Med (Baltim). 2016;95:e3546.

23. Chang ML, Lin YJ, Chang CJ, et al. Occult and Overt HBV Co-Infections Independently Predict Postoperative Prognosis in HCV-Associated Hepatocellular Carcinoma. PLoS One. 2013;8(1):e64891.

24. Chen CW, Cheng JS, Chen TD, Le PH, Ku HP, Chang ML. The irreversible HCV-associated risk of gastric cancer following interferon-based therapy: a joint study of hospital-based cases and nationwide population-based cohorts. Therap Adv Gastroenterol. 2019;12:1756284819855732.

25. Yılmaz N, Karadağ Ö, Kimyon G, Yazıcı A, Yılmaz S, Kalyoncu U, Kaşifoğlu T, Temiz H, Baysal B, Tözün N. Prevalence of hepatitis B and C infections in rheumatoid arthritis and ankylosing spondylitis: A multicenter countrywide study. Eur J Rheumatol. 2014 Jun;1(2):51-4.

26. Maillefert JF, Muller G, Falgarone G, Bour JB, Ratovohery D, Dougados M, Tavernier C, Breban M. Prevalence of hepatitis $C$ virus infection in patients with rheumatoid arthritis. Ann Rheum Dis. 2002 Jul;61(7):635-7.

27. Hsu FC, Starkebaum G, Boyko EJ, Dominitz JA. Prevalence of rheumatoid arthritis and hepatitis $C$ in those age 60 and older in a US population based study. J Rheumatol. 2003 Mar;30(3):455-8. 
28. Sebastiani M, Giuggioli D, Colaci M, et al. HCV-Related Rheumatic Manifestations and Therapeutic Strategies. Curr Drug Targets. 2017;18(7):803-10.

29. Cheng YT, Cheng JS, Lin CH, Chen TH, Lee KC, Chang ML. Rheumatoid factor and immunoglobulin M mark hepatitis C-associated mixed cryoglobulinaemia: an 8-year prospective study. Clin Microbiol Infect. 2020;26(3):366-72.

30. Tung CH, Lai NS, Li CY, Tsai SJ, Chen YC, Chen YC. Risk of rheumatoid arthritis in patients with hepatitis $\mathrm{C}$ virus infection receiving interferon-based therapy: a retrospective cohort study using the Taiwanese national claims database. BMJ Open. 2018 Jul 23;8(7):e021747.

31. Rossi C, Jeong D, Wong S, McKee G, Ahmed Butt Z, Buxton J, Wong J, Darvishian M, Bartlett S, Samji H, Yu A, Binka M, Alvarez M, Adu PA, Tyndall M, Krajden M, Zafar Janjua N. BC Hepatitis Testers Cohort Team.Sustained Virologic Response from Interferon-based Hepatitis C regimes IS associated with Reduced risk of Extrahepatic Manifestations. J Hepatol. 2019 Aug 6. pii: S0168-8278(19)304623.

32. Izumi Y, Komori A, Yasunaga Y, et al. Rheumatoid arthritis following a treatment with IFNalpha/ribavirin against HCV infection. Intern Med. 2011;50(9):1065-8.

33. Pittau E, Bogliolo A, Tinti A, Mela Q, Ibba G, Salis G, Perpignano G. Development of arthritis and hypothyroidism during alpha-interferon therapy for chronic hepatitis C. Clin Exp Rheumatol. 1997 Jul-Aug;15(4):415-9.

34. Niewold TB, Swedler WI. Systemic lupus erythematosus arising during interferon-alpha therapy for cryoglobulinemic vasculitis associated with hepatitis C. Clin Rheumatol. 2005 Apr;24(2):178-81.

35. Zuckerman E, Keren D, Rozenbaum M, et al. Hepatitis C virus-related arthritis: characteristics and response to therapy with interferon alpha. Clin Exp Rheumatol. 2000;18(5):579-84.

36. Wilson LE, Widman D, Dikman SH, Gorevic PD. Autoimmune disease complicating antiviral therapy for hepatitis $C$ virus infection. Semin Arthritis Rheum. 2002 Dec;32(3):163-73.

37. Cacoub P, Comarmond C, Desbois AC, Saadoun D. Rheumatologic Manifestations of Hepatitis C Virus Infection. Clin Liver Dis. 2017;21(3):455-64.

38. Kida T, Umemura A, Kaneshita $S$, et al. Effectiveness and safety of chronic hepatitis $C$ treatment with direct-acting antivirals in patients with rheumatic diseases: A case-series. Mod Rheumatol. 2019;1-7.

39. Safiri S, Kolahi AA, Hoy D, et al. Global, regional and national burden of rheumatoid arthritis 19902017: a systematic analysis of the Global Burden of Disease study 2017. Ann Rheum Dis. 2019;78(11):1463-71.

40. Nikiphorou E, de Lusignan S, Mallen C, et al. Prognostic value of comorbidity indices and lung diseases in early rheumatoid arthritis: a UK population-based study. Rheumatology. 2020;59(6):1296-305.

41. Medina G, Vera-Lastra O, Peralta-Amaro AL, et al. Metabolic syndrome, autoimmunity and rheumatic diseases. Pharmacol Res. 2018;133:277-88.

42. Chung WS, Lin CL, Peng CL, et al. Rheumatoid arthritis and risk of acute myocardial infarction-a nationwide retrospective cohort study. Int J Cardiol. 2013;168(5):4750-4. 
43. Hsu CS, Lang HC, Huang KY, Chao YC, Chen CL. Risks of hepatocellular carcinoma and cirrhosisassociated complications in patients with rheumatoid arthritis: a 10-year population-based cohort study in Taiwan. Hepatol Int. 2018;12(6):531-43.

44. Tung CH, Lai NS, Lu MC, Lee CC. Liver cirrhosis in selected autoimmune diseases: a nationwide cohort study in Taiwan. Rheumatol Int. 2016;36(2):199-205.

45. Ciszek M, Kisiel B, Czerwinski J, et al. Kidney Transplant Recipients With Rheumatic Diseases: Epidemiological Data From the Polish Transplant Registries 1998-2015. Transplant Proc. 2018;50(6):1654-1657.

46. Akasbi N, Houssaini TS, Tahiri L, et al. Rheumatic complications of long term treatment with hemodialysis. Rheumatol Int. 2012;32(5):1161-3.

47. Emamifar A, Levin $K$, Jensen Hansen IM. Patients with newly diagnosed rheumatoid arthritis are at increased risk of diabetes mellitus: an observational cohort study. Patients with newly diagnosed rheumatoid arthritis are at increased risk of diabetes mellitus: an observational cohort study. Acta Reumatol Port. 2017;42(4):310-7.

48. Eder L, Chandran V, Cook R, Gladman DD. The Risk of Developing Diabetes Mellitus in Patients with Psoriatic Arthritis: A Cohort Study. J Rheumatol. 2017;44(3):286-91.

49. Yu ML, Dai CY, Huang JF, et al. A randomised study of peginterferon and ribavirin for 16 versus 24 weeks in patients with genotype 2 chronic hepatitis C. Gut. 2007;56:553-9.

50. Hsu WF, Chen CY, Tseng KC, et al. Sustained virological response to hepatitis $C$ therapy does not decrease the incidence of systemic lupus erythematosus or rheumatoid arthritis. Sci Rep. 2020;10:5372.

\section{Figures}


152,851 patients had HCV diagnosis, HCV test, and received hepatoprotective agents, ribavifin or peg-interferon in 2003-2015
19, 145,884individuals had no HCV

diagnosis, HCV test, and HCV-related

pharmacotherapy in 2003-2015

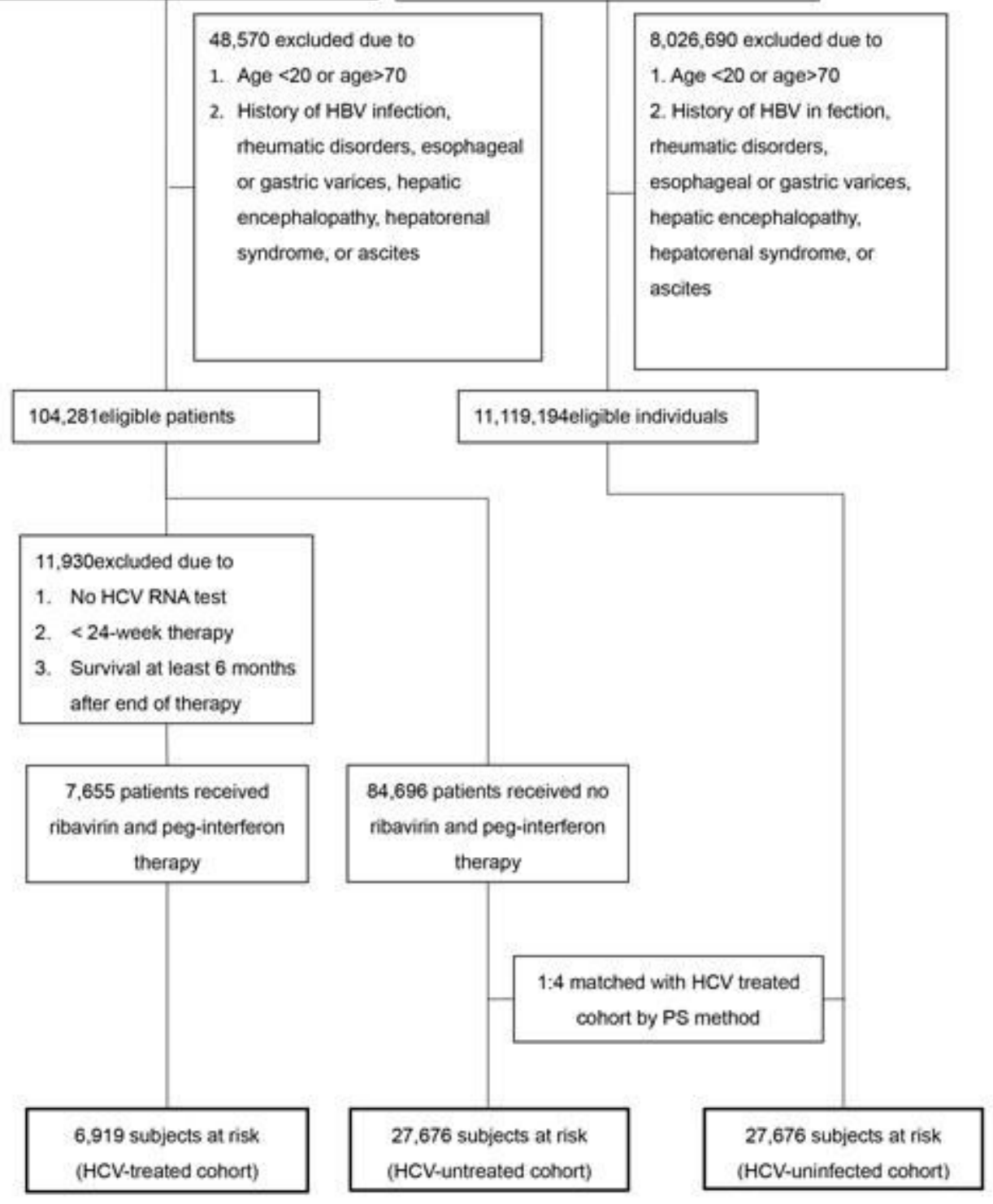

\section{Figure 1}

Flow chart of TNHIRD study subjects selection. TNHIRD: Taiwan National Health Insurance Research Database; HCV: hepatitis C virus; Peg-IFN: pegylated interferon; PS: propensity score. 


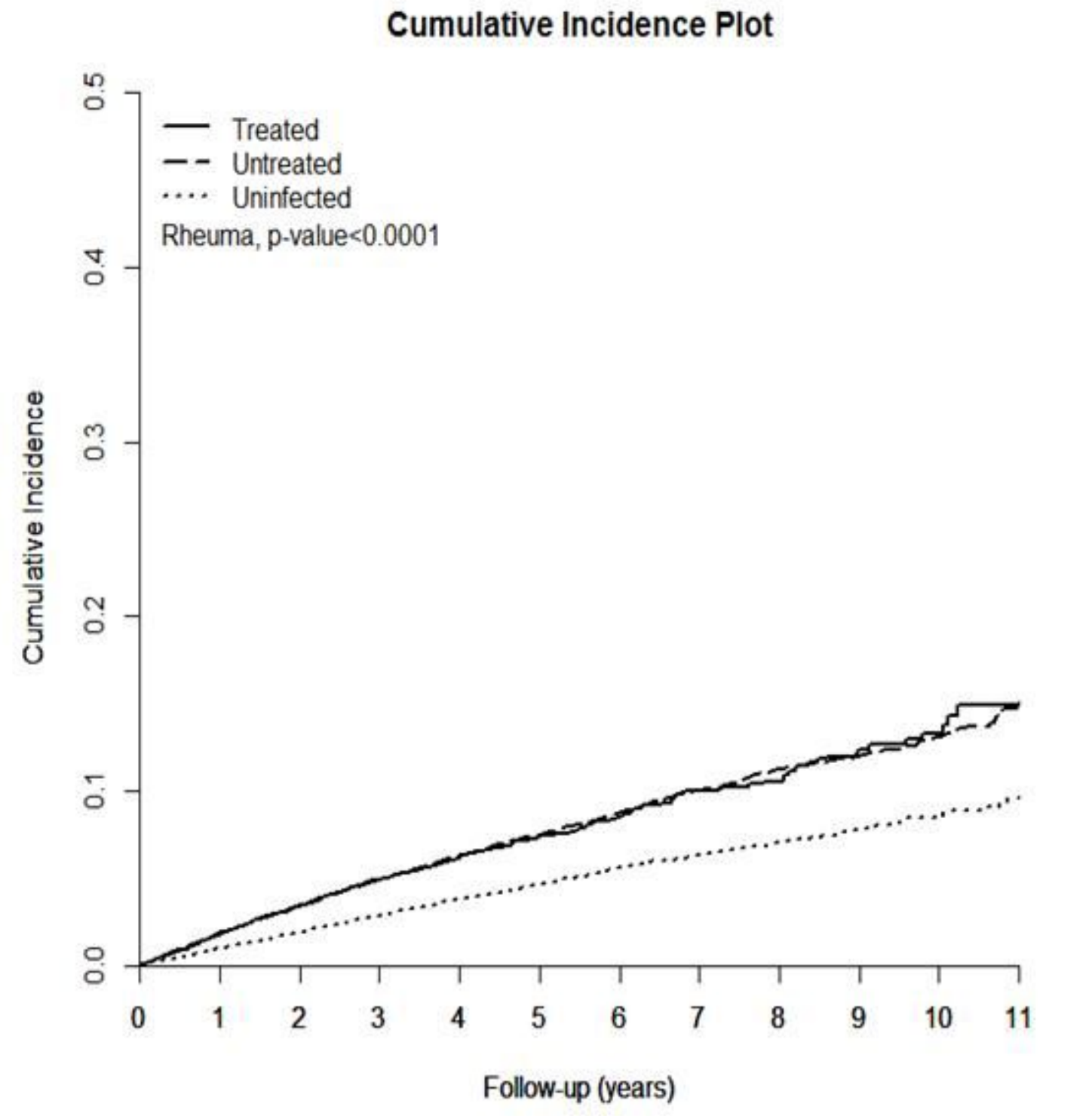

$\begin{array}{lrrrrrrrrrrrr}\text { Treated } & 6919 & 6755 & 6607 & 6437 & 4061 & 1766 & 1080 & 807 & 539 & 361 & 156 & 27 \\ \text { Untreated } & 27676 & 26537 & 25410 & 24321 & 15854 & 9574 & 5725 & 3305 & 2005 & 1244 & 657 & 190 \\ \text { Uninfected } & 27676 & 27156 & 26720 & 26240 & 17319 & 10335 & 6218 & 3760 & 2323 & 1439 & 733 & 249\end{array}$

\section{Figure 2}

Cumulative incidences of rheumatic disorders among the 3 TNHIRD cohorts including HCV-treated, HCVuntreated and HCV-uninfected cohorts. TNHIRD: Taiwan National Health Insurance Research Database; HCV: hepatitis $\mathrm{C}$ virus. 


\begin{tabular}{|c|c|c|c|c|c|c|}
\hline & & & HR & 95\% LCL & $95 \% \mathrm{HCL}$ & $p$-value \\
\hline \multicolumn{7}{|l|}{ HCV (ref=uninfected) } \\
\hline infected & & $\bullet-1$ & 1.671 & 1.562 & 1.788 & $<.0001$ \\
\hline \multicolumn{7}{|l|}{ Gender (ref=Male) } \\
\hline Female & & $\bullet \bullet$ & 1.670 & 1.565 & 1.782 & $<.0001$ \\
\hline \multicolumn{7}{|l|}{ Age (ref<49) } \\
\hline$\geq 49$ & & $\cdot \bullet$ & 1.168 & 1.088 & 1.253 & $<.0001$ \\
\hline \multicolumn{7}{|l|}{ Area (ref $=$ city) } \\
\hline township & & + & 0.976 & 0.895 & 1.066 & 0.5924 \\
\hline rural area & & - 1 & 1.082 & 0.997 & 1.173 & 0.0576 \\
\hline \multicolumn{7}{|l|}{ CCI score $($ ref $=0)$} \\
\hline 1 & & $10-1$ & 1.156 & 1.074 & 1.245 & 0.0001 \\
\hline$\geq 2$ & & $\bullet \bullet-1$ & 1.214 & 1.110 & 1.329 & $<.0001$ \\
\hline \multicolumn{7}{|l|}{ Baseline factor $(\mathrm{ref}=\mathrm{N}$ ) } \\
\hline Liver cirrhosis & $\bullet-1$ & & 0.795 & 0.674 & 0.937 & 0.0062 \\
\hline COPD & & $\bullet-1$ & 1.244 & 1.134 & 1.364 & $<.0001$ \\
\hline ESRD & $\bullet$ & & 0.732 & 0.549 & 0.974 & 0.0326 \\
\hline DM & $\cdot 0$ & & 0.910 & 0.835 & 0.993 & 0.0333 \\
\hline Hypertension & & & 0.979 & 0.908 & 1.055 & 0.5823 \\
\hline Dyslipidemia & & - $\bullet-1$ & 1.205 & 1.108 & 1.310 & $<.0001$ \\
\hline Cardiovascular events & & $\bullet$ & 1.093 & 0.923 & 1.295 & 0.3033 \\
\hline Stroke & $\vdash \bullet$ & & 0.902 & 0.774 & 1.051 & 0.185 \\
\hline
\end{tabular}

\section{Figure 3}

Forrest plot of factors associated with incident rheumatic disorders in the 2 TNHIRD cohorts: HCVpositive (untreated) and HCV-negative (combination of treated and uninfected) cohorts. TNHIRD: Taiwan National Health Insurance Research Database; HR: hazards ratio; LCL: lower confidence interval limit; HCL: higher confidence interval limit; HCV: hepatitis C virus; CCl: Charlson Comorbidity Index score; COPD: Chronic obstructive pulmonary disease; ESRD: end stage renal disease; DM: diabetes mellitus.

\section{Supplementary Files}

This is a list of supplementary files associated with this preprint. Click to download.

- SupplementaryFigure2.tif

- SupplementaryFigure1061320.tif

- SupplementaryTables081020.doc 